\title{
Do Viruses Ever Go Away?
}

\author{
Anessa M. Foxwell, MSN, CRNP, ACHPN ${ }^{1,2}$
}

$\mathbf{O}$ NE DAY DURING QUARANTINE, we were watching Wreck It Ralph as a family. There's a scene when Jane Lynch's character yells at Ralph for talking to the kid behind the screen who is playing the game. One of the insults she uses is to call Ralph "a virus." She ends with, "And viruses never go away." My six-year-old daughter heard this and turned to me, "She said viruses never go away. Is that true?" I stumbled over my words to try to balance truth with reassurance. During the COVID-19 pandemic, my husband and I have been honest about why we all have to stay home, why they are seeing people wear masks, and why school is cancelled. She's heard the word virus, illness, and death. I have explained, in simple terms, what is happening because kids aren't stupid, and they know something is wrong with the world right now.

Being honest with children during difficult times is something I learned from my social work colleagues. I am an oncology and palliative care nurse practitioner and in my 11 years of clinical experience, I have witnessed intense suffering as well as extreme joy in the most difficult times. I have counseled patients through talking to their children or grandchildren about their diagnosis and prognosis. We caution parents to avoid euphemisms and stick to the facts. Hearing horror stories of children told that grandma had a cough and is being cared for the hospital. But when grandma never comes home, the child is fearful that anyone with a cough will need to go to the hospital. Or worse, that when a loved one gets sick, they will never come home. When in reality, grandma had been sick for months or years with lung cancer.

So, to avoid such heartbreak, I am honest with my kids. For instance, we talk about my father-in-law who died before my children were born so that they know his spirit, without ever meeting him. Young kids have trouble with the abstract so looking at a picture helps. Then last year, their greatgrandmother Gigi died. I offered to break the news to them. Me, my six-year-old-daughter, and my four-year-old-son lay on a trundle bed and I told them that Gigi died, and we would not visit her in Florida anymore, but that we always have memories with her. They asked concrete questions such as "so we'll never see her again" and "how did she die" followed quickly by "can we still go to Florida to visit Lulu?" (Lulu is Gigi's daughter, their grandmother.) I answered them truthfully and succinctly to ensure they understood. Kids are resilient and have asked about Gigi intermittently since, but generally go about their day.

Talking about their great-grandmother dying-that was easy. Supporting patients and their families through incred- ibly difficult times - that is challenging but rewarding. As an oncology and palliative care nurse practitioner, I sit with uncertainty in every patient encounter. I am comfortable with uncomfortable emotions. I welcome the challenge of providing some semblance of comfort to very sick patients so that I may serve them. In every patient encounter we face an uncertainty. Will this pain improve? Will I survive this treatment? Will I make it to my daughter's wedding in the summer? How much time do I really have?

Like I said I have become comfortable sitting with this discomfort and unanswerable questions. I can live in the gray and support patients and family members through painful uncertainties. In over a decade of clinical experience, I have also learned to attend to the emotions and uncertainties of my colleagues. I have guided many nurses and physicians through the experience of their first patient death. I have been a shoulder to cry on. I have lent my ear to countless colleagues to allow a space for them to vent, to cry, and to grieve.

But this, this is different. This is using my communication skills to describe crisis, uncertainty, and death, and dying to my children. How am I supposed to answer my beautiful daughter's question? How am I supposed to be honest and soothe her at the same time? How can I answer an unanswerable question?

I say, "Viruses eventually...usually...go away, but sometimes they stay longer than we want them to. I hope this virus goes away soon.' It's the truth and I have to continue to believe it so that I'm not lying to my children.

\section{Funding Information}

A.M.F. is supported by the National Institute of Nursing Research Ruth L. Kirschstein National Research Service Award training program Individualized Care for at Risk Older Adults (T32NR009356) as a predoctoral fellow.

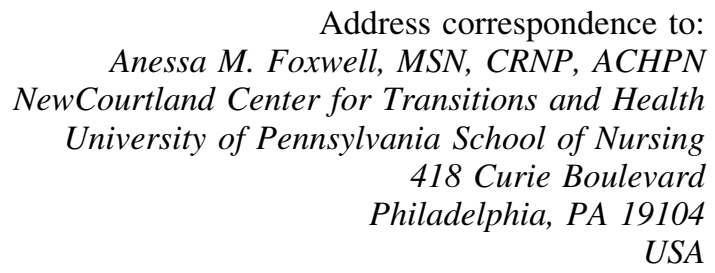

E-mail: anessam@nursing.upenn.edu

\footnotetext{
${ }^{1}$ NewCourtland Center for Transitions and Health, University of Pennsylvania School of Nursing, Philadelphia, Pennsylvania, USA.

${ }^{2}$ Clinical Practices of the University of Pennsylvania, Perlman Center for Advanced Medicine, Philadelphia, Pennsylvania, USA.
} 